altered levels of this thiol and cancer is a recent acquisition, and its clinical significance has yet to be defined. This is the first article reporting an association between MTHFR variant/hyperhomocysteinemia and thymoma, supporting the role of hyperhomocysteinemia as a risk factor for cancer.

\section{References}

1. Moran CA, Suster S, Fishback NF, Koss MN. Primary intrapulmonary thymoma. A clinicopathologic and immunihistochemical study of eight cases. Am J Surg Pathol. 1995;19:304-12.
2. Ishibashi H, Takahashi S, Hosaka T, Shibuya J, Suzuki S, Handa M. Primary intrapulmonary thymoma successfully resected with vascular reconstruction. Ann Thorac Surg. 2003;76:1735-7.

3. Srivastava A, Padilla O, Alroy J, Ucci A, Pilichowska M, Dalcy B, et al. Primary intrapulmonary spindle-cell thymoma with marked granulomatous reaction: report of a case with review of literature. Int J Surg Pathol. 2003;11:353-6.

4. Ray JG, Shmorgun D, Chan WS. Common C677T polymorphism of the methylenetetrahydrofolate reductase gene and the risk of venous thromboembolism: meta-analysis of 31 studies. Pathophysiol Haemost Thromb. 2002;32:51-8.

5. Thurmon TF. Folic acid: miscarriages, anomalies, thromboses, cancers. J La State Med Soc. 2001;153:98-103.

\title{
Anterior transclavicular approach to malignant tumors of the thoracic inlet: Importance of the scapulothoracic articulation
}

\author{
Marc de Perrot, MD, a and Raja Rampersaud, MD, ${ }^{\mathrm{b}}$ Toronto, Canada
}

T he anterior transclavicular approach for lung cancer invading the thoracic inlet was described by Dartevelle and colleagues. ${ }^{1}$ Although this approach provides excellent exposure to the thoracic inlet, it has often been criticized because of potential deformity and dysfunction of the shoulder related to resection of the clavicle. However, the proximal part of the clavicle plays a minor role in the stability and function of the shoulder as long as the integrity of the scapulothoracic articulation is preserved. ${ }^{2,3}$ The scapulothoracic articulation is formed by the attachment of the scapula to the chest wall through the trapezius, latissimus dorsi, rhomboid, levator scapulae, and serratus anterior muscles. ${ }^{4,5}$ Thus, preservation of these muscles and their nerves is crucial to achieve good functional and cosmetic results. We emphasize the importance of preserving the spinal accessory, dorsal scapular, and long thoracic nerves that are running in the posterior cervical triangle and innervate the trapezius, rhomboid, and serratus anterior muscles, and we document the good functional and cosmetic results obtained with this approach despite resection of the clavicle if the scapulothoracic articulation is preserved.

From the Divisions of Thoracic Surgery a and Orthopaedic Surgery, ${ }^{\mathrm{b}}$ Toronto General Hospital and Toronto Western Hospital, University of Toronto, Canada.

Received for publication April 16, 2007; accepted for publication May 14, 2007.

Address for reprints: Marc de Perrot, MD, MSc, Division of Thoracic Surgery, Toronto General Hospital, 9N-961, 200 Elizabeth Street, Toronto, Ontario M5G 2C4, Canada (E-mail: marc.deperrot@uhn.on.ca).

J Thorac Cardiovasc Surg 2007;134:801-3

$0022-5223 / \$ 32.00$

Copyright $\odot 2007$ by The American Association for Thoracic Surgery

doi:10.1016/j.jtcvs.2007.05.022

\section{Clinical Summary}

The anterior transclavicular approach has been described in detail, ${ }^{1}$ and we will therefore limit our description to some specific points only. An incision is made along the sternocleidomastoid muscle and extended horizontally along the third rib. The extension of the incision ranges from the level of the jaw down to the third rib to permit optimal exposure of the thoracic inlet and pulmonary hilum. The sternocleidomastoid and pectoralis major muscles are dissected off the chest wall and elevated together with the skin as a myocutaneous flap. The preservation of a myocutaneous flap is important to obtain adequate healing of the wound. The clavicle is freed up to the point where the subclavian vein crosses behind the clavicle.

The spinal accessory nerve should be identified in the upper part of the cervical incision at the posterior edge of the sternocleidomastoid muscle lateral to the internal jugular vein. The nerve then runs in the posterior cervical triangle in front of the levator scapulae and trapezius muscles, which form the lateroposterior border of the surgical field behind the elevated myocutaneous flap (Figure 1).

Division of the scalenus anterior muscle will expose the brachial plexus and the subclavian artery. At this point, branches of the fifth (C5), sixth (C6), and seventh (C7) cervical nerve roots passing through the body of the scalenus medius muscle can be identified emerging on the lateral aspect of this muscle just above the brachial plexus (Figure 1). These small branches (1-2 mm) must be preserved when the scalenus medius muscle is divided from the first rib because they will form the dorsal scapular (branches of C5) and long thoracic nerves (branches of C5, C6, and $\mathrm{C} 7$ ) innervating the rhomboid and serratus anterior muscles, respectively.

Division of the first and second rib at the costosternal junction and the third rib along the posterior axillary line provides excellent exposure to the pulmonary hilum to perform the upper lobectomy and mediastinal lymph node dissection (Figure 1). If involved by 


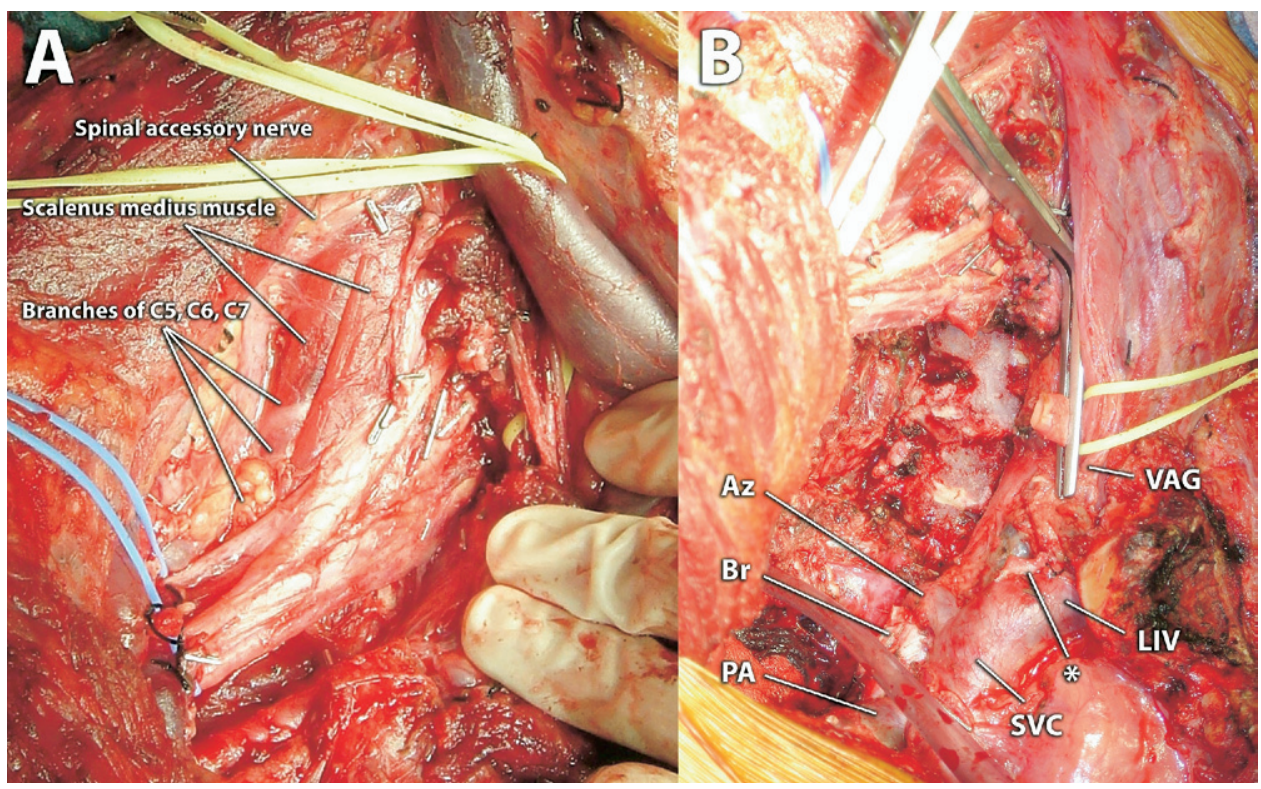

Figure 1. A, Exposure obtained after division of the transverse cervical vessels and section of the scalenus anterior muscle. Branches of the spinal accessory, dorsal scapular, and long thoracic nerves must be localized and preserved in the posterior cervical triangle. The spinal accessory nerve is extremely vulnerable in the posterior cervical triangle because of its superficial location and the presence of surroundings fat tissue. Branches of the dorsal scapular (C5) and long thoracic nerves (C5, C6, C7) emerge through the scalenus medius muscle and can easily be damaged when the scalenus medius muscle is divided from the first rib. B, Exposure obtained after resection of a tumor involving the T1 nerve root, subclavian artery, vertebral artery, subclavian vein, phrenic nerve, ribs 1 to 3 , and lateral part of the spine from the first to the third thoracic vertebrae. An upper lobectomy was easily performed through this incision after division of the first 2 ribs along the sternum and division of the third rib along the posterior axillary line. We recommend not combining a posterolateral thoracotomy with the anterior transclavicular approach to preserve the integrity of the trapezius, latissimus dorsi, rhomboid, and serratus anterior muscles. The bronchial stump from the upper lobe, main pulmonary artery, azygos vein, superior vena cava, right vagus and recurrent nerve, and left innominate vein can be identified. Note the right innominate vein is stapled at the confluence between the left innominate vein and the superior vena cava $(*)$. The vascular clamps are located on the subclavian artery. Br, Bronchial; PA, pulmonary artery; $A z$, azygos vein; SVC, superior vena cava; Vag, vagus; LIV, left innominate vein.
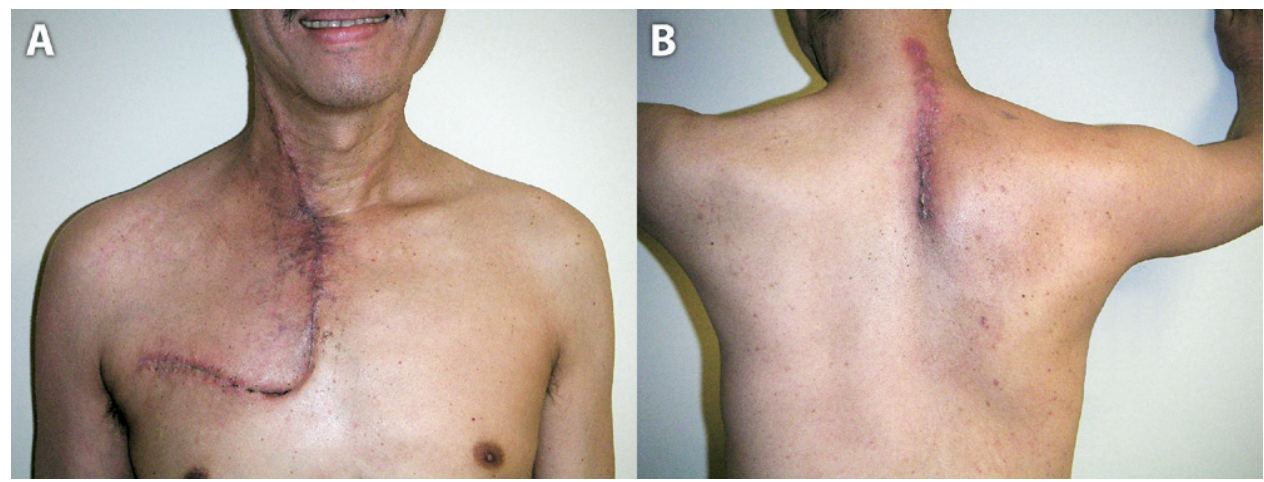

Figure 2. At 3 weeks postoperatively, there is excellent function of the shoulder with no winging of the scapula and minimal cervical defect despite complete resection of the first 2 ribs, partial resection of the third rib, partial resection of the spine, and resection of the inner part of the clavicle. Note the incision extends from the level of the jaw to the third rib to obtain good exposure of both the thoracic inlet and the pulmonary hilum. A posterior midline incision was used in this patient to section the transverse processes of T1 to T3 and to section the spinal nerve roots of T1, T2, and $\mathrm{T} 3$ at the edge of the neural foramen away from the tumor. Surgery was performed after induction chemoradiation therapy $(2$ cycles of cisplatin and etoposide concurrently with $45 \mathrm{~Gy}$ of radiation). A, View from the front. B, View from the back. 
the tumor, the subclavian artery is resected and reanastomosed end to end or with a ringed polytetrafluoroethylene (6- or 8-mm) graft.

The sternal component of the sternocleidomastoid muscle must be sutured back to the manubrium with heavy sutures when closing the incision. If the spinal accessory, dorsal scapular, and long thoracic nerves are preserved along with the trapezius, latissimus dorsi, rhomboid, levator scapulae, and serratus anterior muscles, this approach results in minimal shoulder dysfunction and cosmetic defect despite resection of the inner part of the clavicle (Figure 2).

\section{Discussion}

The anterior transclavicular approach with resection of the inner part of the clavicle and extension of the incision along the third rib gives excellent exposure from the thoracic inlet down to the pulmonary hilum. This approach allows dissection of the cervical structures and completion of the upper lobectomy and mediastinal lymph node dissection through the same incision under excellent conditions. Compared with the hemiclamshell approach, this approach provides excellent exposure to the distal subclavian vessels and allows direct anterior and anterolateral approach to the spine and brachial plexus. The anterior clavicular sparing approach described by several authors, including Grunenwald and Spag- giari, ${ }^{6}$ can provide adequate exposure to the thoracic inlet but offers limited view of the upper mediastinum and often requires an additional thoracotomy to perform the lobectomy and mediastinal lymph node dissection. If the inner part of the clavicle is removed, it is important, however, to preserve the spinal accessory, dorsal scapular, and long thoracic nerves in the posterior cervical triangle and to maintain the integrity of the trapezius, latissimus dorsi, rhomboid, and serratus anterior muscles by avoiding a posterolateral thoracotomy to obtain good cosmetic and functional results.

\section{References}

1. Dartevelle PG, Chapelier AR, Macchiarini P, Lenot B, Cerrina J, Le Roy Ladurie F, et al. Anterior transcervical-thoracic approach for radical resection of lung tumors invading the thoracic inlet. $J$ Thorac Cardiovasc Surg. 1993;105:1025-34.

2. Abbott LC, Lucas DB. The function of the clavicle. Ann Surg. 1954; 140:583-99.

3. Owens BD, Goss TP. The floating shoulder. J Bone Joint Surg. 2006; 88:1419-24.

4. Pouliart N, Gagey O. Significance of the latissimus dorsi for shoulder instability. Clin Anat. 2005;18:493-9.

5. Williams GR Jr, Shakil M, Klimkiewicz J, Iannotti JP. Anatomy of the scapulothoracic articulation. Clin Orthop Relat Res. 1999;359:237-46.

6. Grunenwald D, Spaggiari L. Transmanubrial osteomuscular sparing approach for apical chest tumors. Ann Thorac Surg. 1997;63:563-6.

\title{
Osteomalacia associated with a fibroblast growth factor-23 secreting chest wall tumor
}

\author{
Subroto Paul, MD, Michael Kurtz, BS, and Steven J. Mentzer, MD, Boston, Mass
}

\section{Clinical Summary}

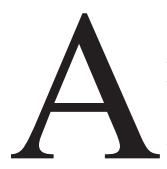
previously healthy 32-year-old man had a 9-month history of progressive rib, pelvic, and foot pain. Skeletal radiographs and bone scintigraphy revealed multiple fractures of the ribs, pelvis, and right foot.

Blood testing demonstrated low plasma phosphate levels (1.5 $\mathrm{mg} / \mathrm{dL}$; normal $2.4-5.0 \mathrm{mg} / \mathrm{dL})$ but normal calcium $(9.2 \mathrm{mg} / \mathrm{dL}$; normal $8.8-10.5 \mathrm{mg} / \mathrm{dL}$ ) and immunoreactive parathyroid hor-

From the Division of Thoracic Surgery, Brigham and Women's Hospital, Harvard Medical School, Boston, Mass.

Received for publication March 22, 2007; revisions received May 3, 2007; accepted for publication May 22, 2007.

Address for reprints: Steven J. Mentzer, MD, Room 259, Brigham \& Women's Hospital, 75 Francis S, Boston MA 02115 (E-mail: smentzer@ partners.org).

J Thorac Cardiovasc Surg 2007;134:803-5

$0022-5223 / \$ 32.00$

Copyright $\odot 2007$ by The American Association for Thoracic Surgery doi:10.1016/j.jtcvs.2007.05.025 mone levels (39 pg/mL; normal $11-80 \mathrm{pg} / \mathrm{mL}$ ). A 24-hour urine collection demonstrated phosphaturia (1593 mg/24 hours; normal 500-1200 mg/24 hours), suggesting a phosphate wasting disorder. Since 25 vitamin D (34 ng/mL; normal 20-57 ng/mL) and 1,25 vitamin $\mathrm{D}(19 \mathrm{pg} / \mathrm{mL} ; 18-62 \mathrm{pg} / \mathrm{mL})$ levels were within normal limits, a recently recognized disorder of paraneoplastic fibroblast growth factor (FGF)-23 production was investigated. Serum immunoassays for FGF-23 were initially found to be high normal (173 RU/mL; normal <180 RU/mL), but levels obtained the day of surgery were elevated (432 RU/mL).

As part of a systemic soft tissue and skeletal survey for an FGF-23 secreting tumor, a chest computed tomographic scan demonstrated an expansile and destructive lesion in the right posterior eighth rib (Figure 1, A). A fine needle aspiration biopsy revealed benign spindle cells with osteoclast-like cells and hemosiderin deposition.

Because no other bony or soft tissue tumors were identified, surgical resection of the chest wall tumor was recommended. At the time of surgery, thoracoscopic examination of the tumor demonstrated neovascularization of the parietal pleura (Figure 1, B). A complete excision of the chest wall mass required excision of a portion of the eighth rib (Figure 1,C). Gross evaluation of the tumor demonstrated multiple cystic spaces. The patient had an 